\title{
Stimulation of Thrombopoiesis in Mice by Human Recombinant Interleukin 6
}

Ronald J. Hill," M. Kim Warren, ${ }^{\star}$ and Jack Levin*

${ }^{*}$ Departments of Laboratory Medicine and Medicine, University of California School of Medicine and Veterans Administration

Medical Center, San Francisco, California 94121; and ${ }^{\ddagger}$ Department of Cell Biology, Cetus Corporation, Emeryville, California 94608

\begin{abstract}
To date, testing of various cytokines for the stimulation of blood cell production has not demonstrated a consistent effect on peripheral platelet levels. In this report, we provide evidence that human recombinant IL-6 increased platelet production in mice, as measured by both peripheral platelet levels and $\left[{ }^{75}\right.$ Se]selenomethionine $\left({ }^{75} \mathrm{SeM}\right)$ incorporation into newly forming platelets. Peripheral white blood cell counts also were increased, but only to a modest extent, and hematocrit values were unchanged. A dose-response relationship between the amount of IL-6 administered and platelet count, ${ }^{75} \mathrm{SeM}$ incorporation, and white blood cell count was demonstrated. Detectable megakaryocyte and granulocyte-macrophage colonyforming cells in mice that had received IL-6 also were increased in both bone marrow and spleen. These results demonstrate the ability of a purified, recombinant protein to stimulate platelet production in vivo. (J. Clin. Invest. 1990. 85:1242-1247.) interleukin 6 - megakaryocyte • thrombopoietin • platelet production • colony-forming cells
\end{abstract}

\section{Introduction}

Although regulation of platelet production has been studied for over two decades, a clear understanding of the mechanisms that control thrombopoiesis has not been achieved. Platelet production can be stimulated either endogenously, by production of acute thrombocytopenia, or exogenously, by administration of fractionated plasma from animals in which the peripheral platelet levels had been severely decreased (reviewed in references 1-3). A substance that stimulates platelet production also is present in the supernatant of cultures of human embryonic kidney cells (HEKC) ${ }^{1}$ (4). Partial purification (from a number of sources) of the activity that stimulates platelet production, designated thrombopoietin (TPO), has been reported (5-8). However, TPO has not been completely isolated and characterized; this has prevented large scale production through DNA cloning technology. Without large quantities of pure TPO, it has not been possible to adequately

Parts of this study have been previously reported (1989. Blood. 74[Suppl. 1]:207a. [Abstr.]).

Address reprint requests to Dr. R. J. Hill, Veterans Administration Medical Center, 113A, 4150 Clement Street, San Francisco, CA 94121.

Received for publication 18 August 1989 and in revised form 14 November 1989.

1. Abbreviations used in this paper: $\mathrm{CFC}$, colony-forming cell; CSF, colony-stimulating factor; GM, granulocyte-macrophage; HEKC, human embryonic kidney cell; MK, megakaryocyte; ${ }^{75} \mathrm{SeM},\left[{ }^{75} \mathrm{Se}\right] \mathrm{Se}-$ lenomethionine; TPO, thrombopoietin.

The Journal of Clinical Investigation, Inc.

Volume 85, April 1990, 1242-1247 analyze hormonal stimulation of platelet production in vivo. Purification and characterization of TPO remains an important goal for research into thrombopoiesis both to provide a probe for studying the regulation of platelet production and to potentially allow intervention in clinical settings that require acceleration of platelet production.

Attempts to stimulate thrombopoiesis in vivo, using recombinant factors that are currently being tested for their ability to enhance production of other blood cells, have not been consistently successful. Although high doses of purified recombinant erythropoietin have been reported to increase platelet production in rodents $(9,10)$, it does not increase peripheral platelet levels in humans at the dosages used for patients with end-stage renal disease (11). The recent observations that the cytokine IL-6 stimulates megakaryocyte (MK) growth and maturation in vitro (12-14), as well as increases MK ploidy in vitro (14), suggest that the potential effect of IL-6 on platelet production should be more extensively studied.

IL-6 is a cytokine with a wide range of in vitro biological activities (reviewed in reference 15 ) including antiviral activity (interferon $\beta_{2}$ ), B cell stimulation, hybridoma growth factor activity, hepatocyte stimulatory activity, and $\mathrm{T}$ lymphocyte activation. IL-6 exhibits various hematopoietic colony-stimulating and differentiation-inducing activities in murine and human bone marrow cell culture systems (16-20). IL-6 also has been found to synergize with other growth factors including IL-3 $(12,13,16,21,22)$, IL-4 (13), granulocyte-macrophage colony-stimulating factor (GM-CSF) (20) and macrophage CSF (23). Interestingly, the study with macrophage CSF did not demonstrate synergy between IL-6 and IL-3, GM-CSF, granulocyte CSF, or erythropoietin, using purified human bone marrow progenitor cells (23).

In vivo, a single injection of $0.01-0.8 \mu \mathrm{g}$ of IL-6 into rats caused a rapid and transient increase in peripheral blood neutrophils and lymphocytes (potentially due to demargination), which subsided by $24 \mathrm{~h}$ after administration (24). Bone marrow myeloid hyperplasia and erythroid hyperplasia, associated with peripheral blood reticulocytosis, also was observed. It is important to note that no changes in MKs (the precursors for circulating platelets) were observed. Administration of IL-6 to mice for $7 \mathrm{~d}$ by osmotic pumps (1-50 $\mu \mathrm{g} /$ mouse per $\mathrm{d}$ ) resulted in an increase of both spleen and GM colony-forming units in the spleen but not in the bone marrow (25); no peripheral blood measurements were made. A study in mice of the effect of IL-6 $(10 \mu \mathrm{g} /$ mouse per d) on recovery after bone marrow transplantation demonstrated increases in the number of spleen and bone marrow cells and peripheral white blood cells, but no effect on platelets and red blood cells (26). Recently, it has been demonstrated that administration of human recombinant IL-6 produces elevated platelet levels and increased MK diameter in mice (27).

In this study, we have examined the effect of pure human recombinant IL-6 expressed in SF9 insect cells $(28,29)$, on platelet production in mice. We have measured not only pe- 
ripheral platelet levels, but also the rate of platelet production, to rule out alterations in distribution of the platelet mass that might result in increased platelet levels. Other peripheral blood cell levels also were measured. In addition, the effect of administration of IL-6 to mice on MK and GM colony-forming cells (CFC) detectable in the spleen and bone marrow was examined.

\section{Methods}

Administration of human recombinant IL-6. Purified human recombinant IL-6 was kindly provided by Cetus Corp., Emeryville, CA. IL-6 bioactivity was quantified utilizing the IL-6-dependent murine hybridoma cell line B9 (30), using IL-6 commercially available from Amgen Biologicals (Thousand Oaks, CA) as the assay standard. The Amgen IL-6 has a specific activity of 1-2 $\times 10^{7} \mathrm{U} / \mathrm{mg}$, measured as stimulation of IgG secretion by the B cell line SKW-6.4; $1 \mathrm{U}=$ half maximal secretion on day 4 . The specific activity of the insect cell-expressed IL-6 was similar to the Amgen IL-6 in the B9 assay (10 U/ng). We confirmed that the IL- 6 used for the present study was capable of stimulating murine MK growth in vitro, as previously described (12, 13) by demonstrating that in the presence of murine IL-3 $(10 \mathrm{U} / \mathrm{ml}$; DNAX, Palo Alto, CA), addition of IL-6 $(5-200 \mathrm{ng} / \mathrm{ml})$ to agar cultures of murine bone marrow cells $(50,000$ cells $/ 1 \mathrm{ml}$ culture) resulted in increased formation of MK colonies.

The route of administration of IL- 6 chosen for this study was subcutaneous injection, in order to maintain plasma levels of IL-6 longer than after intravenous or intraperitoneal administration. The disappearance of IL-6 from plasma after intravenous administration has been found to be biphasic with half-lives of 3 and $55 \mathrm{~min}$, respectively (31). We postulated that subcutaneous injection would provide a slower rate of delivery into the plasma, resulting in a longer period of biological activity. IL-6 was administered to Swiss Webster mice $(25-30 \mathrm{~g}$; Bantin and Kingman, Fremont, $\mathrm{CA})$ in solutions $(0.5 \mathrm{ml} / \mathrm{in}-$ jection) that contained $140 \mathrm{mM} \mathrm{NaCl}$ (bacteriostatic saline; Abbott Laboratories, North Chicago, IL), $100 \mu \mathrm{g} / \mathrm{ml}$ bovine serum albumin (Fraction V; Sigma Chemical Co., St. Louis, MO), and IL-6. Injections of IL-6 (or control solution containing all components except IL-6) were performed eight times during a 54-h period (three injections during each of the first two 24-h periods; two injections during the final 6-h period).

Platelet production. $\left[{ }^{75} \mathrm{Se}\right]$ Selenomethionine $\left({ }^{75} \mathrm{SeM}\right)$ incorporation into newly formed platelets was used as a measure of the rate of platelet production, as previously described $(32,33) .{ }^{75} \mathrm{SeM}$ was injected intraperitoneally into control and experimental animals $2 \mathrm{~h}$ after the final injection of test materials. $16 \mathrm{~h}$ after the isotope injection, the animals were killed and the levels of ${ }^{75} \mathrm{SeM}$ in platelets, isolated from whole blood collected by cardiac puncture, as previously described (32), were measured. The percent of the total injected isotope present in circulating platelets was calculated.
Peripheral blood cell levels. Peripheral platelet and white blood cell levels were determined using an electronic particle counter (Coulter Electronics Inc., Hialeah, FL, as described previously (34). Hematocrit values were determined with a microhematocrit centrifuge (model MB; International Equipment Co., Needham Hts., MA).

CFCs. Single cell suspensions of bone marrow or spleen cells from control and experimental mice were prepared and cultured in $0.3 \%$ agar, in a fully humidified atmosphere of $10 \% \mathrm{CO}_{2}$ in air. A source of growth factor, obtained from the supernatants of spleen cells cultured in the presence of pokeweed mitogen, was added to each culture (35, 36). MK- and GM-CFCs were quantified on the basis of colonies formed after $7 \mathrm{~d}$, when the frequency of MK colonies is maximum. GM colonies were identified by morphology in wet cultures with a $40 \times$ stereo microscope. MK colonies (three or more cells) were identified by staining for the enzyme acetylcholinesterase after the cultures were dried, as previously described $(37,38)$. Bone marrow and spleen cells were collected when animals were killed for platelet isolation (i.e., $18 \mathrm{~h}$ after the final IL-6 injection) and were grown in culture as indicated above. Total numbers of detectable CFCs per femur or spleen were calculated by multiplying the total number of colonies per number of cells plated (frequency) by the total number of cells obtained from a single femur or spleen.

\section{Results}

To test the effect of IL- 6 on platelet production, IL- 6 was administered in eight subcutaneous injections during a 54-h period (as described in Methods). The extended injection schedule was used to allow immature MKs adequate time to become mature platelet-releasing cells, thus providing a range of potential target cells for IL-6. Multiple injections are required because of the relatively short plasma half-life of IL-6. Table I shows the effect of a total dose of $8 \mu \mathrm{g}$ of IL-6 on platelet production. The rate of appearance and levels of the isotopes ${ }^{35} \mathrm{~S}$ or ${ }^{75} \mathrm{SeM}$ in circulating platelets provide the basis for a well characterized assay for platelet production $(32,33$, 39,40 ); these radionuclides label newly synthesized platelets via protein synthesis in the cytoplasm of the platelet precursor cell, the MK. The $100 \%$ increase in ${ }^{75} \mathrm{SeM}$ incorporation is indicative of a very large increase in the rate of thrombopoiesis. We have found that administration of partially purified TPO to normal animals usually produces only a $30-50 \%$ increase in ${ }^{75} \mathrm{SeM}$ incorporation $(8,32)$. The marked increase in platelet production was further substantiated by the increase in peripheral platelet levels (Table I). Peripheral white blood cell counts were not elevated sufficiently, at this dose, to achieve statistical significance. The hematocrit value also was not changed by administration of IL-6.

Table I. The Effect of IL-6 on Platelet Production and Peripheral Blood Cell Levels

\begin{tabular}{lccc}
\hline & Peripheral platelet count & $\begin{array}{c}\text { Peripheral white } \\
\text { blood cell count }\end{array}$ \\
\hline & \% of total injected isotope & & Hematocrit \\
& $\left(\times 10^{2}\right)$ & platelets $/ \mu l \times 10^{-6}$ & cells $/ \mu l$ \\
Control & $1.95 \pm 0.09(20)$ & $1.262 \pm 0.030(21)$ & $3,680 \pm 330(21)$ \\
IL-6 & $3.91 \pm 0.22(17)^{*}$ & $1.607 \pm 0.049(19)^{*}$ & $4,200 \pm 320(19)$
\end{tabular}

Human recombinant IL-6 was administered subcutaneously to Swiss Webster mice (25-30 g) at a dose of $1 \mu \mathrm{g} / \mathrm{injection}(8 \mu \mathrm{g}$ total dose per mouse). Mean values $\pm 1 \mathrm{SE}$ are shown. The numbers in parentheses indicate the number of animals that were analyzed. In this table, the results of three completely independent experiments have been pooled. The IL-6 used for these experiments was from two separately prepared batches. For statistical analysis, the data were analyzed by the Mann-Whitney $U$ test. $\quad P<0.0001$. 
Table II. The In Vivo Effect of IL-6 on Murine MKand GM-CFCs in the Bone Marrow and the Spleen

\begin{tabular}{lcclcc}
\hline & \multicolumn{2}{c}{ Total bone marrow CFC } & & \multicolumn{2}{c}{ Total spleen CFC } \\
\cline { 2 - 3 } \cline { 5 - 6 } & MK & GM & & MK & GM \\
\hline Control & $3,900 \pm 1,100$ & $41,170 \pm 3,160$ & & $3,390 \pm 500$ & $7,760 \pm 560$ \\
IL-6 & $12,270 \pm 1,550^{*}$ & $94,560 \pm 2,140^{*}$ & & $7,580 \pm 740^{*}$ & $33,630 \pm 1670^{*}$
\end{tabular}

IL-6 was administered to mice as indicated in Table I. Total CFCs per femur or spleen were calculated as described in Methods. The results of three separate experiments have been averaged; the cell suspensions from two animals were combined for each experiment. A total of six experimental and six control animals were studied in the three experiments presented. Statistical analysis was performed as for Table I.

$* P<0.005$

The previous observations that IL-6 increased the detectability of MK-CFC in vitro remained to be confirmed in vivo. Therefore, we examined the effect of administration of IL-6 (total dose of $8 \mu \mathrm{g}$ ) to mice on bone marrow and spleen CFCs (Table II). IL-6 increased the numbers of detectable MK- and GM-CFCs derived from both bone marrow and spleen. This is in agreement with a previous study that demonstrated an increase in GM-CFC in mice after a 7-d infusion of IL-6 by osmotic pumps (25). MK-CFC were not examined in the previous study.

We determined whether a dose-related response could be demonstrated for the effects of IL- 6 on platelet production and CFC. Table III demonstrates the effects of various doses of IL-6 on ${ }^{75} \mathrm{SeM}$ incorporation, peripheral platelet and white blood cell levels, and detectable colony-forming cells. Maximal effect on platelet production appeared to occur between a total dose of 4.0 and $16 \mu \mathrm{g}$ per animal. There was a lesser response at $1.6 \mu \mathrm{g}$ per animal and no effect at $0.4 \mu \mathrm{g}$. The peripheral white blood cell count, although increased in a dose-dependent manner, achieved a statistically significant difference from control mice only at the highest dose tested. In the bone marrow, detectable MK-CFC were increased at a total dose of $1.6 \mu \mathrm{g}$ or higher, but detectable GM-CFC were

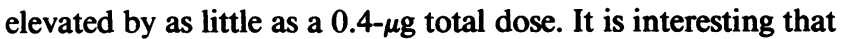
the apparently greater sensitivity to IL-6 of GM-CFC in the bone marrow (relative to MK-CFC) was not manifested by a comparable increase of peripheral white blood cells. In the spleen, alterations of the numbers of detected MK and GM colonies paralleled each other with a minimum total dose of $1.6 \mu \mathrm{g}$ required to produce an effect. Our ability to produce a dose-related response is further evidence that the administered IL-6 was responsible for the observed effects on hematopoiesis in vivo. All injection solutions used for the dose-response experiments presented in Table III were tested for endotoxin contamination by the sensitive Limulus amebocyte lysate assay (41). No endotoxin was detectable up to a total dose of 4 $\mu \mathrm{g}$. The $8-\mu \mathrm{g}$ total dose ( $1 \mu \mathrm{g}$ IL-6/0.5 ml injection) contained $<0.1 \mathrm{pg} / \mathrm{ml}$ of endotoxin and the $16-\mu \mathrm{g}$ total dose $(2 \mu \mathrm{g}$ IL-6/0.5 ml injection) contained $0.1-1 \mathrm{pg} / \mathrm{ml}$ of endotoxin. These concentrations (in the volumes injected) do not produce physiologic effects.

After determining a range of doses of IL- 6 that produced stimulation of platelet production when administered during a 54-h period, we examined the effect of shortening the injection schedule. Administration of $4 \mu \mathrm{g}$ of IL-6 (a dose that stimulated platelet production in previous experiments), starting 24 $h$ before sampling of tissues (IL-6 was administered in two equal doses during a 6-h period), did not result in elevation of peripheral platelet levels or ${ }^{75} \mathrm{SeM}$ incorporation into newly formed platelets.

\section{Discussion}

The demonstration of stimulation of platelet production by a pure recombinant growth factor is clearly important. The models previously employed to study stimulation of thrombopoiesis have relied on perturbation of animals by bone marrow suppression or peripheral destruction of platelets. In this study, we have demonstrated stimulation of thrombopoiesis in normal animals using only a pure recombinant protein. The effects are greater than we have observed with short term administration of TPO, which is only available in partially purified

Table III. The Effect of Various Doses of IL-6 on Murine Hematopoiesis In Vivo

\begin{tabular}{|c|c|c|c|c|c|c|c|}
\hline \multirow[b]{2}{*}{ Dose of IL-6 } & \multirow{2}{*}{$\begin{array}{c}{ }^{75} \mathrm{SeM} \\
\text { incorporation }\end{array}$} & \multirow[b]{2}{*}{$\begin{array}{l}\text { Peripheral platelet } \\
\text { count }\end{array}$} & \multirow{2}{*}{$\begin{array}{l}\text { Peripheral } \\
\text { white blood } \\
\text { cell count }\end{array}$} & \multicolumn{2}{|c|}{ Total bone marrow CFC } & \multicolumn{2}{|c|}{ Total spleen CFC } \\
\hline & & & & MK & GM & MK & GM \\
\hline total $\mu \mathrm{g} /$ mouse & $\begin{array}{c}\text { \% of total injected } \\
\text { isotope } \times 10^{2}\end{array}$ & Platelets $/ \mu l \times 10^{-6}$ & 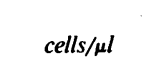 & $c f c / f e m u r$ & $c f c / f e m u r$ & $c f c /$ spleen & $c f c /$ spleen \\
\hline Control (20) & $1.95 \pm 0.09$ & $1.262 \pm 0.030$ & $3,680 \pm 330$ & $3,130 \pm 770$ & $38,880 \pm 2,070$ & $3,130 \pm 410$ & $7,179 \pm 560$ \\
\hline $0.4 \quad$ (5) & $1.56 \pm 0.17$ & $1.132 \pm 0.017$ & $2,640 \pm 320$ & $3,890 \pm 200$ & $54,520 \pm 710^{*}$ & $3,090 \pm 10$ & $5,430 \pm 360$ \\
\hline 1.6 & $2.57 \pm 0.21^{\ddagger}$ & $1.366 \pm 0.046$ & $3,380 \pm 360$ & $6,890 \pm 330^{\ddagger}$ & $65,930 \pm 330^{\S}$ & $5,130 \pm 80^{\ddagger}$ & $10,470 \pm 670^{\ddagger}$ \\
\hline$(5)$ & $4.20 \pm 0.37^{\S}$ & $1.563 \pm 0.037^{\S}$ & $4,110 \pm 500$ & $6,060 \pm 10^{\ddagger}$ & $78,100 \pm 1,420^{\S}$ & $1,780 \pm 60$ & $7,810 \pm 60$ \\
\hline (11) & $4.20 \pm 0.21^{11}$ & $1.615 \pm 0.073^{\prime \prime}$ & $4,760 \pm 430$ & $14,890 \pm 1,460^{*}$ & $91,170 \pm 2,960^{\S}$ & $6,380 \pm 560^{*}$ & $36,100 \pm 1,700^{*}$ \\
\hline 16.0 & $3.82 \pm 0.17^{\S}$ & $1.623 \pm 0.070^{\S}$ & $5,890 \pm 910^{\ddagger}$ & $8,320 \pm 1,400^{\ddagger}$ & $91,940 \pm 2,910^{\S}$ & $8,600 \pm 630^{\ddagger}$ & $29,700 \pm 1,830^{\ddagger}$ \\
\hline
\end{tabular}

Human recombinant IL-6 was administered to mice to achieve the total doses indicated. ${ }^{75}$ SeM incorporation, peripheral platelet and white blood cell levels, and numbers of CFCs were measured as described in Methods. The numbers in parentheses indicate the number of animals that were individually studied for ${ }^{75} \mathrm{SeM}$ incorporation, peripheral platelet counts, and white blood cell counts. The values for CFCs are based on multiple dilutions of cell suspensions pooled from two animals. The CFC values for the 8.0- $\mu \mathrm{g}$ dose are based on two separate groups of animals with two sampled from each group. The control CFC values are based on three separate groups of animals with two sampled from each group. Mean values are presented $\pm 1 \mathrm{SE}$. Statistical analysis was performed as for Table $1 .{ }^{*} P<0.01 ;{ }^{\ddagger} P<0.05 ;{ }^{\S} P<0.001 ;{ }^{\|} P<0.0001$. 
preparations. Increased platelet levels, an important manifestation of increased platelet production, have usually not been associated with stimulation of thrombopoiesis by partially purified TPO $(8,42)$. Our observations that IL-6 results in augmentation of platelet levels is important in contrast to the cytokines IL-2, IFN- $\gamma$, IL- $1 \beta$, and IL-3, which have little effect on peripheral blood cells when administered alone (43-45). Therefore, IL-6 is potentially a very important probe for the study of regulation of platelet production. In addition, encouraging results using colony stimulating factors to diminish the leukopenia associated with chemotherapy (46) suggest that thrombocytopenia, also associated with many of the same therapies, may become the limiting toxicity for the use of bone marrow suppressive agents. If IL-6 can stimulate platelet production in humans, as it does in mice, then use of a combination of colony stimulating factors and IL-6 may diminish the two major limiting toxicities associated with chemotherapy, allowing more aggressive and potentially more effective use of marrow suppressive drugs for cancer patients and patients with AIDS.

A recently published study reported that in vivo administration of IL-6 to mice produced an increase in peripheral platelet levels (27). However, increased levels of circulating platelets do not necessarily establish that platelet production has been stimulated. An alteration in the distribution of the circulating platelet mass (e.g., a decreased splenic pool) could produce elevated platelet levels although platelet production remained unaffected. Administration of IL- $1 \beta$ to normal mice produces thrombocytopenia that is eliminated by splenectomy, and therefore is not caused by a decrease in platelet production (47). Therefore, our observations that both isotope incorporation into newly forming platelets (a well-characterized assay for the rate of platelet production) and peripheral platelet levels are increased after IL-6 administration, provide convincing evidence that in vivo administration of IL-6 stimulates platelet production in mice.

Our observations that administration of IL- 6 produced an increase in MK- and GM-CFC in both bone marrow and spleen is in striking contrast to the recent study of Ishibashi et al. which did not detect an increase in either MK- or GM-CFC in bone marrow after administration of IL-6 (27). The spleen, which may be a more sensitive indicator of stimulated murine thrombopoiesis $(36,48)$, was not studied. A previous investigation also demonstrated an increase in GM-CFC in the spleen of mice after administration of IL- 6 for $7 \mathrm{~d}$ by osmotic pump (25). However, no changes were observed in the bone marrow. The reason for these discrepancies is not clear, but our observations are important because they suggest that multiple stages of megakaryocytopoiesis are affected by IL-6. The effects on CFC could be indirect, occurring as a result of depletion of more mature cell populations, and therefore the discrepancies among the observations of effects on CFC could result from differences in the level of stimulation of hematopoiesis.

We do not believe that the increase in MK-CFC is responsible for the observed increase in platelet production, because our experimental protocol does not allow sufficient time for MK-CFC to generate mature platelet-producing MKs. The increase in platelet production is more likely due to an effect on maturing and mature MKs. This concept is supported by our observation that GM-CFCs were elevated by a dose of IL-6 that produced no effect on peripheral leukocyte counts. Similarly, in mice, administration of low doses of 5-fluorouracil or production of acute thrombocytopenia produces increases in splenic MK-CFC that occur too late to account for the resulting rebound thrombocytosis $(49,50)$. Our observation that IL-6 elevated numbers of detectable MK-CFC in the bone marrow is in contrast to previous findings that acute thrombocytopenia does not produce a comparable increase in bone marrow MK-CFC (48-51). However, the relationship between detectable numbers of CFC and peripheral platelet levels remains unclear.

Ishibashi et al. also failed to detect the effect of IL-6 on peripheral leukocyte levels which we observed (27). Although a statistically significant increase in leukocyte count was achieved in our studies only at the 16- $\mu$ g dose, the dose-response relationship between the dose of IL-6 and the resulting leukocyte counts observed after administration of lower doses of IL-6 suggests that IL-6 does affect leukocyte levels. Although the hematocrit value did not increase in our studies, reticulocytosis and erythroid hyperplasia after administration of IL-6 has been described (24). Therefore, IL-6 may increase the hematocrit if administered for an adequate period of time. These observations are important because they indicate that the hematopoietic effects of IL-6 are not completely lineage specific, although the stimulation of platelet production is more dramatic than has been consistently observed after administration of other cytokines.

An important question raised by our study is the nature of the potential relationship between IL- 6 and TPO. Parallels exist between the activities of IL- 6 and those of partially purified sources of TPO, including support of the growth of murine MK colonies (in the presence of a CSF) and single MKs in vitro (1-3). HEKC culture supernatant, which also supports murine MK growth in vitro (in the presence of a CSF), has been shown to contain IL-6 (52). Therefore, at least some of the in vitro activities of HEKC supernatant may result from the presence of IL-6. Interestingly, HEKC supernatant also has been shown to support the growth of GM colonies $(53,54)$, another in vitro activity of IL-6. Our current results suggest that the presence of IL- 6 could also account for some of the in vivo thrombopoiesis-stimulating activity of HEKC supernatant. Whether the thrombopoiesis-stimulating activity present in the plasma of animals after production of acute thrombocytopenia also is due to IL- 6 remains to be investigated. However, our preliminary findings (data not provided) indicate that IL-6 levels in murine plasma are not elevated at the appropriate time-points after acute thrombocytopenia. TPO levels are elevated 4-6 h after induction of acute thrombocytopenia $(5,8)$ but IL- 6 levels were found to be normal at both 4 and $6 \mathrm{~h}$. This would suggest that TPO and IL-6 are not the same molecule although they may both act upon the same regulatory system.

Elucidation of the mechanism by which IL-6 stimulates platelet production in mice will provide important insights into humoral regulation of thrombopoiesis. Ishibashi et al. demonstrated an increase in MK size after administration of IL-6 (27). It will be important to establish whether other changes in MKs observed after acute thrombocytopenia (e.g., increased number, and DNA content) can be produced by administration of IL-6 to mice with normal platelet levels. This would provide strong evidence that IL- 6 can stimulate the normal regulatory mechanism of thrombopoiesis, possibly in conjunction with TPO or by a similar, independent mechanism. 


\section{Acknowledgments}

We thank Georgiann Baker and Francine C. Levin for assistance with ${ }^{75} \mathrm{SeM}$ assays and $\mathrm{CFC}$ assays, respectively. In addition, we are grateful to James Devlin, Robin Clark, David Lowe, Duane Inlow, Mary Poulhazan, and Robert Drummond for the vector construction, production, and purification of IL-6.

This work was supported in part by the Veterans Administration.

\section{References}

1. Hill, R. J., and J. Levin. 1989. Regulators of thrombopoiesis: their biochemistry and physiology. Blood Cells (Berl.). 15:141-166.

2. Mazur, E. M. 1987. Megakaryocytopoiesis and platelet production: a review. Exp. Hematol. (NY). 15:340-350.

3. McDonald, T. P. 1988. Thrombopoietin: its biology, purification and characterization. Exp. Hematol. (NY). 16:201-205.

4. McDonald, T. P., R. Clift, R. D. Lange, C. Nolan, I. I. E. Tribby, and G. H. Barlow. 1975. Thrombopoietin production by human embryonic kidney cells in culture. J. Lab. Clin. Med. 85:59-66.

5. Evatt, B. L., D. P. Shreiner, and J. Levin. 1974. Thrombopoietic activity of fractions of rabbit plasma: studies in rabbits and mice. $J$. Lab. Clin. Med. 83:364-371.

6. McDonald, T. P., M. Cottrell, R. Clift, J. A. Khouri, and M. D. Long. 1985. Studies on the purification of thrombopoietin from kidney cell culture medium. J. Lab. Clin. Med. 106:162-174.

7. Vannucchi, A. M., A. Grossi, D. Rafanelli, P. R. Ferrini, and G. Ramponi. 1988. Partial purification and biochemical characterization of human plasma thrombopoietin. Leukemia (Baltimore). 2:236-240.

8. Hill, R., and J. Levin. 1986. Partial purification of thrombopoietin using lectin chromatography. Exp. Hematol. (NY). 14:752759.

9. Berridge, M. V., J. K. Fraser, J. M. Carter, and F. K. Lin. 1988. Effects of recombinant human erythropoietin on megakaryocytes and on platelet production in the rat. Blood. 72:970-977.

10. McDonald, T. P., M. B. Cottrell, R. E. Clift, W. C. Cullen, and F. K. Lin. 1987. High doses of recombinant erythropoietin stimulate platelet production in mice. Exp. Hematol. (NY). 15:719-721.

11. Eschbach, J. W., J. C. Egrie, M. R. Downing, J. K. Browne, and J. W. Adamson. 1987. Correction of the anemia of end-stage renal disease with recombinant human erythropoietin. N. Engl. J. Med. 316:73-78.

12. Warren, M. K., L. B. Conroy, and J. D. Stelzner. 1989. The role of interleukin-6 and interleukin-1 in megakaryocyte development. Exp. Hematol. (NY). 17:1095-1099.

13. Rennick, D., J. Jackson, G. Yang, J. Wideman, F. Lee, and S. Hudak. 1989. Interleukin-6 interacts with interleukin-4 and other hematopoietic growth factors to selectively enhance the growth of megakaryocytic, erythroid, myeloid, and multipotential progenitor cells. Blood. 73:1828-1835.

14. Ishibashi, T., H. Kimura, T. Uchida, P. Friese, and S. A. Burstein. 1989. Human interleukin 6 is a direct promoter of maturation of megakaryocytes in vitro. Proc. Natl. Acad. Sci. USA. 86:5953-5957.

15. Kishimoto, T. 1989. The biology of interleukin-6. Blood. 74:1-10.

16. Ikebuchi, K., G. G. Wong, S. C. Clark, J. N. Ihle, Y. Hirai, and M. Ogawa. 1987. Interleukin 6 enhancement of interleukin 3-dependent proliferation of multipotential hemopoietic progenitors. Proc. Natl. Acad. Sci. USA. 84:9035-9039.

17. Wong, G. G., J. A. S. Witek-Giannotti, P. A. Temple, R. Kriz, C. Ferenz, R. M. Hewick, S. C. Clark, K. Ikebuchi, and M. Ogawa 1988. Stimulation of murine hemopoietic colony formation by human IL-6. J. Immunol. 140:3040-3044.

18. Suda, T., Y. Yamaguchi, J. Suda, Y. Miura, A. Okano, and Y. Akiyama. 1988. Effect of interleukin 6 (IL-6) on the differentiation and proliferation of murine and human hemopoietic progenitors. Exp. Hematol. (NY). 16:891-895.
19. Sachs, L., J. Lotem, and Y. Shabo. 1989. The molecular regulators of macrophage and granulocyte development. Role of MGI-2/IL6. Ann. NY. Acad. Sci. 557:417-437.

20. Caracciolo, D., S. C. Clark, and G. Rovera. 1989. Human interleukin-6 supports granulocytic differentiation of hematopoietic progenitor cells and acts synergistically with GM-CSF. Blood. 73:666670 .

21. Leary, A. G., K. Ikebuchi, Y. Hirai, G. G. Wong, Y. C. Yang, S. C. Clark, and M. Ogawa. 1988. Synergism between interleukin-6 and interleukin-3 in supporting proliferation of human hematopoietic stem cells: comparison with interleukin-1 $\alpha$. Blood. 71:1759-1763.

22. Hoang, T., A. Haman, O. Goncalves, G. G. Wong, and S. C. Clark. 1988. Interleukin-6 enhances growth factor-dependent proliferation of the blast cells of acute myeloblastic leukemia. Blood. 72:823826.

23. Bot, F. J., L. Eijk, L. Broeders, L. A. Aarden, and B. Lowenberg. 1989. Interleukin-6 synergizes with M-CSF in the formation of macrophage colonies from purified human marrow progenitor cells. Blood. 73:435-437.

24. Ulich, T. R., J. del Castillo, and K. Guo. 1989. In vivo hematologic effects of recombinant interleukin- 6 on hematopoiesis and circulating numbers of RBCs and WBCs. Blood. 73:108-110.

25. Suzuki, C., A. Okano, F. Takatsuki, Y. Miyasaka, T. Hirano, T. Kishimoto, D. Ejima, and Y. Akiyama. 1989. Continuous perfusion with interleukin 6 (IL-6) enchances production of hematopoietic stem cells (CFU-S). Biochem. Biophys. Res. Commun. 159:933-938.

26. Okano, A., C. Suzuki, F. Takatsuki, Y. Akiyama, K. Koike, T. Nakahata, T. Hirano, T. Kishimoto, K. Ozawa, and S. Asano. 1989. Effects of interleukin-6 on hematopoiesis in bone marrow-transplanted mice. Transplantation (Baltimore). 47:738-740.

27. Ishibashi, T., H. Kimura, Y. Shikama, T. Uchida, S. Kariyone, T. Hirano, T. Kishimoto, F. Takatsuki, and Y. Akiyama. 1989. Interleukin-6 is a potent thrombopoietic factor in vivo in mice. Blood. 74:1241-1244.

28. Maiorella, B., D. Inlow, A. Shauger, and D. Harano. 1988. Large-scale insect cell-culture for recombinant protein production. Bio/technology. 6:1406-1410.

29. Devlin, J., P. E. Devlin, R. Clark, E. C. O'Rourke, C. Levenson, and D. F. Mark. 1989. Novel expression of chimeric plasminogen activators in insect cells. Bio/technology. 7:286-292.

30. Helle, M., L. Boeije, and L. A. Aarden. 1988. Functional discrimination between interleukin 6 and interleukin 1. Eur. J. Immunol. 18:1535-1540.

31. Castell, J. V., T. Geiger, V. Gross, T. Andus, E. Walter, T. Hirano, T. Kishimoto, and P. C. Heinrich. 1988. Plasma clearance, organ distribution and target cells of interleukin-6/hepatocyte-stimulating factor in the rat. Eur. J. Biochem. 177:357-361.

32. Hill, R. J., P. Stenberg, P. Sullam, and J. Levin. 1988. Use of arabino-galactan to obtain washed murine platelets free of contaminating plasma proteins and appropriate for studies of function, morphology, and thrombopoiesis. J. Lab. Clin. Med. 111:73-83.

33. Evatt, B. L., and J. Levin. 1969. Measurement of thrombopoiesis in rabbits using ${ }^{75}$ selenomethionine. J. Clin. Invest. 48:16151626.

34. Bull, B. S., M. A. Schneiderman, and G. Brecher. 1965. Platelet counts with the Coulter counter. Am. J. Clin. Pathol. 44:678-688.

35. Levin, J., F. C. Levin, D. G. Penington, and D. Metcalf. 1981 Measurement of ploidy distribution in megakaryocyte colonies obtained from culture: with studies of the effects of thrombocytopenia. Blood. 57:287-297.

36. Levin, J., F. C. Levin, and D. Metcalf. 1980. The effects of acute thrombocytopenia on megakaryocyte-CFC and granulocyte-macrophage-CFC in mice: studies of bone marrow and spleen. Blood. 56:274-283.

37. Karnovsky, M. J., and L. Roots. 1964. A “direct-coloring" thiocholine method for cholinesterases. J. Histochem. Cytochem. 12:219-221.

38. Williams, N., and H. Jackson. 1982. Kinetic analysis of mega- 
karyocyte numbers and ploidy levels in developing colonies from mouse bone marrow cells. Cell Tissue Kinet. 15:483-494.

39. Odell, T. T., Jr., and T. P. McDonald. 1964. Two mechanisms of sulfate- $\mathrm{S}^{35}$ uptake by blood platelets of rats. Am. J. Physiol. 206:580-584.

40. Penington, D. G. 1969. Assessment of platelet production with ${ }^{75}$ Se selenomethionine. Br. Med. J. 4:782-784.

41. Levin, J., P. A. Tomasulo, and R. S. Oser. 1970. Detection of endotoxin in human blood and demonstration of an inhibitor. J. Lab. Clin. Med. 75:903-911.

42. Levin, J., F. C. Levin, D. F. Hull III, and D. G. Penington. 1982. The effects of thrombopoietin on megakaryocyte-CFC, megakaryocytes, and thrombopoiesis: with studies of ploidy and platelet size. Blood. 60:989-998.

43. Talmadge, J. E., M. Schneider, J. Keller, F. Ruscetti, D. Longo, R. Pennington, O. Bowersox, and H. Tribble. 1989. Myelostimulatory activity of human interleukin-2 in mice. Blood. 73:1458-1467.

44. Donahue, R. E., J. Seehra, M. Metzger, D. Lefebvre, B. Rock, S. Carbone, D. G. Nathan, M. Garnick, P. K. Sehgal, D. Laston, et al. 1988. Human IL-3 and GM-CSF act synergistically in stimulating hematopoiesis in primates. Science (Wash. DC). 241:1820-1823.

45. Metcalf, D., C. G. Begley, G. R. Johnson, N. A. Nicola, A. F. Lopez, and D. J. Williamson. 1986. Effects of purified bacterially synthesized murine multi-CSF (IL-3) on hematopoiesis in normal adult mice. Blood. 68:46-57.

46. Klingemann, H. G. 1989. Clinical applications of recombinant human colony-stimulating factors. CMAJ (Can. Med. Assoc. J.). 140:137-142.

47. Williams, D. E., and P. J. Morrissey. 1989. Alterations in mega- karyocyte and platelet compartments following in vivo IL- $1 \beta$ administration to normal mice. J. Immunol. 142:4361-4365.

48. Kimura, H., G. M. Segal, M. Y. Lee, and J. W. Adamson. 1985. Megakaryocytopoiesis in the rat: response to thrombocytopenia induced by exchange transfusion. Exp. Hematol. (NY). 13:1048-1054.

49. Levin, J., F. C. Levin, D. Metcalf, and D. G. Penington. 1981. The effects of acute thrombocytopenia upon megakaryocyte-CFC and granulocyte-macrophage-CFC in the bone marrow and spleen of mice: with studies of ploidy distribution in megakaryocyte colonies. In Megakaryocyte Biology and Precursors: In Vitro Cloning and Cellular Properties. B. Evatt, R. F. Levine, and N. T. Williams, editors. Elsevier/North-Holland, Amsterdam. 179-190.

50. Yeager, A. M., J. Levin, and F. C. Levin. 1983. The effects of 5-fluorouracil on hematopoiesis: studies of murine megakaryocyteCFC, granulocyte-macrophage-CFC, and peripheral blood cell levels. Exp. Hematol. (NY). 11:944-952.

51. Burstein, S. A., J. W. Adamson, S. K. Erb, and L. A. Harker. 1981. Megakaryocytopoiesis in the mouse: response to varying platelet demand. J. Cell. Physiol. 109:333-341.

52. Withy, R. M., L. F. Rafield, J. P. Winslow, S. Yankelev, and C. L. Oppenheimer. 1989. Human embryonic kidney (HEK) cells produce interleukin-6 (IL-6), which promotes megakaryocyte maturation in vitro. J. Cell. Biochem. 13C(Suppl.):20. (Abstr.)

53. McDonald, T. P., and R. K. Shadduck. 1982. Comparative effects of thrombopoietin and colony-stimulating factors. Exp. Hematol. (NY). 10:544-550.

54. Petursson, S. R., and P. A. Chervenick. 1988. Comparative effects of thrombopoietic-stimulatory factor and spleen cell-conditioned medium on megakaryocytopoiesis in a short-term bone marrow liquid culture system. Exp. Hematol. (NY). 16:660-666. 